\title{
Frequency and evolution of oculomotor palsies in diabetic patients in the Instituto Mexicano de Oftalmología
}

\section{Frecuencia y evolución de las parálisis oculomotoras en el paciente diabético en el Instituto Mexicano de Oftalmología}

\author{
Teresa Díaz-Flores ${ }^{1}$, David Romero-Apis ${ }^{2}$ and J. Fernando Pérez-Pérez ${ }^{2 *}$ \\ ${ }^{1}$ Servicio de Oftalmología General; ${ }^{2}$ Servicio de Estrabismo y Oftalmología Pediátrica. Instituto Mexicano de Oftalmología IAP, Querétaro, Qro., \\ Mexico
}

\begin{abstract}
Introduction: Paralytic strabismus in diabetic patients is more common in adults and more frequent in those with a long history of diabetes. It affects the cranial nerves III, IV and VI. Methods: We analyzed data from the clinical records of the Strabismus Service of the Instituto Mexicano de Oftalmología, from January 2015 to March 2017, looking for patients with diagnosis of oculomotor nerves palsy (III, IV, VI). We also analyzed the evolution between the patients treated with botulinum toxin injection and those without treatment (observation). Descriptive statistics parameters were analyzed. Results: The most frequent etiology of oculomotor palsies was the microvascular with $76 \%$. The most affected cranial nerve in the general population was the VI nerve with $41.33 \%$. The most affected cranial nerve in diabetic patients was the III cranial nerve with 24 cases, followed by the VI cranial nerve with 22 cases and the least affected was the IV cranial nerve with 7 cases. Botulinum toxin was applied to 17 patients and 36 patients were observed without treatment. Of the 17 patients that required injection, 5 had paralysis of the III cranial nerve and 12 of the VI cranial nerve. Conclusions: The III cranial nerve was the most affected in diabetic patients. Botulinum toxin is effective in the majority of cases and provides a fast and effective response. The response to botulinum toxin varies depending on the magnitude of the deviation, with a slower recovery in cases of greater deviation.
\end{abstract}

Key words: Oculomotor palsies. Diabetes. Botulinum toxin.

\section{Resumen}

Introducción: El estrabismo paralítico en pacientes diabéticos es más común en adultos y más frecuente en aquellos que presentan diabetes de larga evolución. Afecta a los nervios craneales III, IV y VI. Métodos: Se tomaron los datos de los expedientes clínicos del Servicio de Estrabismo del Instituto Mexicano de Oftalmología, de enero de 2015 a marzo de 2017, en busca de los pacientes con diagnóstico de parálisis oculomotora (III, IV, VI). Además se analizó la evolución de los pacientes tratados con toxina botulínica y aquellos que se mantuvieron en observación. Se analizaron parámetros de estadística descriptiva. Resultados: La etiología de las parálisis oculomotoras más frecuente fue la microvascular con un $76 \%$. El nervio craneal más afectado en la población general fue el VI, en un 41.33\%. En diabéticos, fue el III, con 24 casos, seguido

Correspondence:

*José Fernando Pérez-Pérez

Circuito exterior, Estadio Corregidora, s/n

Del. Colinas del Cimatario

Date of reception: 28-06-2018

Date of acceptance: $15-10-2018$

C.P. 76099, Querétaro, Qro., Mexico

E-mail: fernando.perez@imoiap.edu.mx

DOI: 10.24875/RMOE.M18000046
Available online: 11-01-2019

Rev Mex Oftalmol (Eng). 2019;93(1):22-26 www.rmo.com.mx 0187-4519/@ 2018 Sociedad Mexicana de Oftalmología. Publicado por Permanyer México. Este es un artículo Open Access bajo la licencia CC BY-NC-ND (http://creativecommons.org/licenses/by-nc-nd/4.0/). 
del VI, con 22 casos, y el menos afectado fue el IV, con 7 casos. Como tratamiento, se aplicó toxina botulíica a 17 pacientes y en 36 se optó por observación. De los 17 pacientes inyectados, 5 tenían parálisis del nervio craneal III, y 12, parálisis del VI. Conclusiones: El nervio craneal III fue el que se afectó en mayor proporción en la población diabética. La toxina botulínica es efectiva en la mayoría de los casos y proporciona una respuesta rápida y efectiva. La respuesta terapéutica de la desviación a la toxina botulínica varía dependiendo de la magnitud de la desviación, y la recuperación es más lenta a mayor grado de desviación.

Palabras clave: Parálisis oculomotoras. Diabetes. Toxina botulínica.

\section{Introduction}

Paralytic strabismus in patients with diabetes mellitus is considered a microangiopathy that affects the III, IV and $\mathrm{VI}$ cranial nerves ${ }^{1,2}$. In diabetic patients it is more common in adults and more frequent in those with a long history of diabetes. Other risk factors are the presence of retinopathy, nephropathy and neuropathy ${ }^{2}$. In retrospective studies, the Caucasian diabetic population shows a prevalence of paralytic strabismus of $0.4 \%$, while an observational and population study conducted in 2016 in Saudi Arabia showed a prevalence of $0.32 \%$ in a database of 64,351 diabetics in the period from 2000 to 2010. It was found that the most affected nerve was the $\mathrm{VI}$ cranial nerve with a percentage of $53.11 \%$, followed by the III and IV nerves, with a percentage of 36.36 and $2.8 \%$, respectively ${ }^{2}$.

Third cranial nerve paralysis may be complete or incomplete. When it is complete, the patient presents ptosis, mydriasis and lack of accommodation, as well as exotropia and hypotropia in the primary position of gaze. In ductions we observe limitation to elevation, adduction and depression. In cases of incomplete III cranial nerve paralysis, the clinical presentation will depend on the muscles affected. The most frequent etiology is microvascular (diabetes, systemic hypertension) ${ }^{1,3-5}$. An aneurysm should be ruled out through neuroimaging studies when the paralysis is acute, painful and with pupillary involvement. If there is not pupillary involvement, it probably has a microvascular etiology 3,5 .

The IV cranial nerve innervates only the superior oblique muscle 1 . The most frequent acquired cause of IV nerve paralysis is blunt cranial trauma, followed by intracranial tumors, microvascular pathology and intracranial aneurysms $\mathrm{s}^{1,5,6}$.

Paralysis of the sixth cranial nerve is the most frequent oculomotor paralysis. The sixth cranial nerve innervates the lateral rectus muscle, and its paralysis produces esotropia in the primary position of gaze $\mathrm{e}^{1,7,8}$. The most frequent acquired cause is microvascular due to diabetes, atherosclerosis or hypertension; other causes are traumatic, neoplastic and secondary to aneurysms $s^{1,5,7,8}$.
The recovery of most cases of oculomotor paralysis occurs within 6 months. When the paralysis is of microvascular etiology, it resolves completely in 2 to 3 months. The inflammatory cases resolve in a high percentage of patients. The traumatic cases that are not resolved in 3 months will leave sequels. Neoplastic cases usually progress ${ }^{5,9}$.

In 1973, botulinum toxin was used for the first time to treat infantile esotropia ${ }^{10}$. It has subsequently been used for the treatment of strabismus secondary to various etiologies, such as trauma, oculomotor paralysis, retinal detachment, cataract, glaucoma, psychomotor retardation, etc., showing a significant improvement in the deviation after its use $e^{9,11-13}$. The objective of our research was to obtain real data on the prevalence and etiology of oculomotor paralysis, as well as their evolution in the Mexican population.

\section{Methods}

A retrospective and descriptive study of patients with oculomotor paralysis was conducted at the Mexican Institute of Ophthalmology, through the review of clinical records. For the application of botulinum toxin, the following technique was performed: prior instillation of topical anesthesia with tetracaine, with a $27 \mathrm{G}$ needle and with transconjunctival muscle clamp, $5 \mathrm{IU}$ of botulinum toxin were applied in the medial rectus of $7.5 \mathrm{IU}$ in the lateral rectus, depending on the type of paralysis. In the case of IV nerve paralysis, 2.5 IU were applied in the inferior oblique. Data were taken from the database of the Strabismus Service in the period from February 2015 to February 2017, searching for patients with a diagnosis of oculomotor paralysis (III, IV, VI). We evaluated the frequency and analyzed the evolution of patients with oculomotor paralysis and diabetes who were treated with botulinum toxin and of those patients whose treatment consisted on observation and treatment with vitamin B-complex. The information was captured into an Excel database, analyzing descriptive statistics parameters. 


\section{Results}

In this two-year period, 75 cases of patients diagnosed with oculomotor paralysis were found. Of these, 36 were female and 39 were male. The average age was 55.24 years, with a range of 2 to 88 years.

The most affected cranial nerve in general was the $\mathrm{VI}$ in $41.33 \%(n=31)$, followed by the III cranial nerve in $37.33 \%(n=28)$ and, finally, the IV in $21.33 \%(n=16)$ (Fig. 1).

Considering the etiology, according to our series, the most frequent was the microvascular with 57 cases (76\%). Of these, $26.6 \%$ had diabetes mellitus associated with systemic hypertension; $44 \%$ only diabetes mellitus and $5.3 \%$ only systemic hypertension (Table 1 ).

Regarding the patients with a history of diabetes mellitus and oculomotor paralysis, the III cranial nerve was the most affected with 24 cases, followed by the VI cranial nerve with 22 cases, and the IV cranial nerve with 7 cases (Fig. 2).

The average age of patients with diabetes mellitus and oculomotor paralysis was 63.11 years, with a range of 38 to 88 years. Botulinum toxin was applied to $17 \mathrm{pa}$ tients $(32 \%)$, and $36(68 \%)$ patients opted for observation and treatment with oral vitamin B-complex. The distribution of the affected cranial nerves in the 17 injected patients was: 5 with III cranial nerve palsy (29\%) and 12 with VI cranial nerve palsy (71\%). Of the patients with conservative treatment, half had paralysis of the III cranial nerve $(n=18), 31 \%(n=11)$ of the $\mathrm{VI}$ and $19 \%(n=7)$ of the IV.

\section{Evolution}

\section{Third nerve paralysis}

The initial range of deviation in patients with III cranial nerve paralysis to whom botulinum toxin was applied was 8 to 55 prism diopters (PD) of exotropia, with an average of $23 \mathrm{PD}$. In the final measurement, the range of the deviation was from 5 to $16 \mathrm{PD}$, with an average of $9 \mathrm{PD}$ in an average time of 2 months. In three patients it was not possible to assess the measurement of the final deviation because they did not attend the subsequent consultations.

The initial measurement in patients with III cranial nerve palsy with conservative treatment was from 12 to $45 \mathrm{PD}$ and an average of $30 \mathrm{PD}$, and the final measurement, from 0 to $40 \mathrm{PD}$ in a period that ranged from 1 week to 7 months. In 10 patients, the measurement

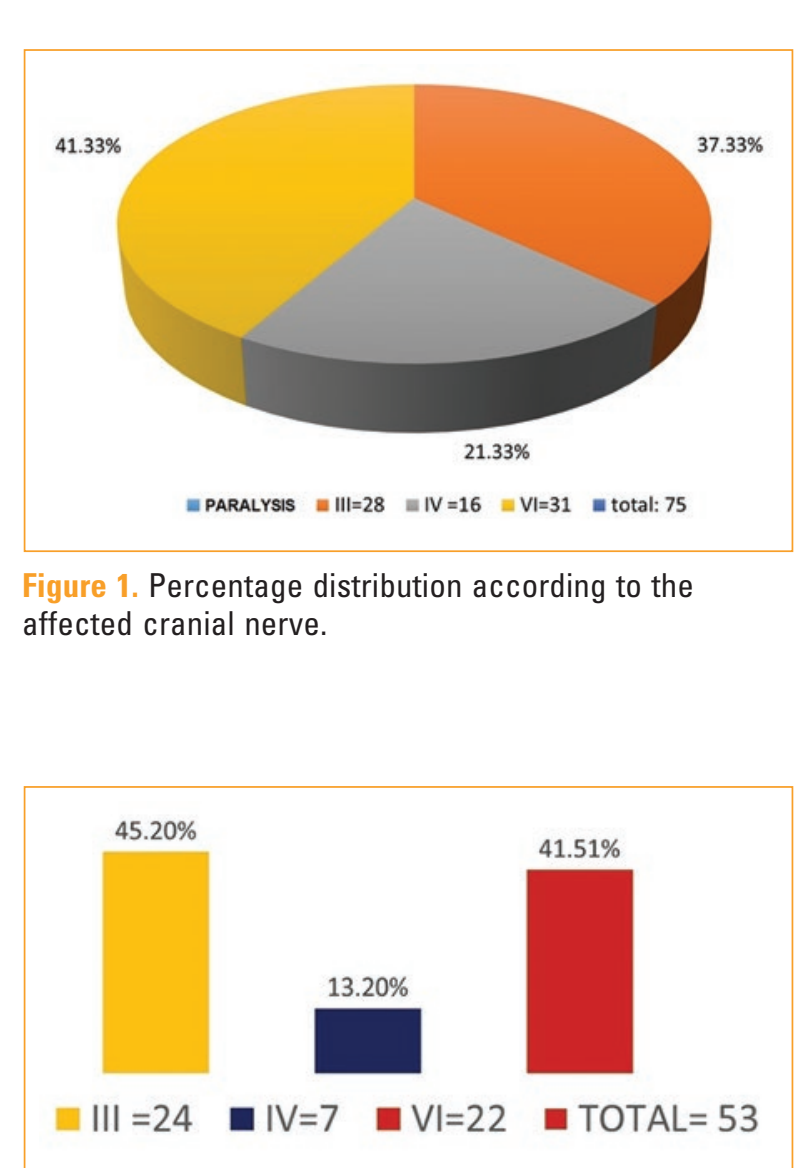

Figure 2. Percentage distribution according to the affected cranial nerve in patients with diabetes mellitus.

Table 1. Etiology of oculomotor paralysis

\begin{tabular}{|l|c|c|c|}
\hline Etiology & Number of cases & $\%$ \\
\hline Congenital & 7 & 9.3 \\
\hline Metabolic (microvascular) & 57 & $\frac{3}{7}$ & 76 \\
\hline Indeterminate & 8 & $\frac{0}{2}$ & 10.7 \\
\hline Secondary (neurological alteration) & 1 & & 1.3 \\
\hline Traumatic & 2 & 7 & 2.7 \\
\hline Total & 75 & $\frac{c}{c}$ & 100 \\
\hline
\end{tabular}

Information obtained from clinical records.

of the final deviation could not be assessed because they did not attend the subsequent consultations.

\section{Sixth nerve paralysis}

As for the diabetic patients who received botulinum toxin, the range of initial deviation was 4 to $45 \mathrm{PD}$ of 
Table 2. Range and average of the initial and final deviation measurement in patients injected with botulinum toxin

\begin{tabular}{|c|c|c|c|c|c|}
\hline \multirow[t]{2}{*}{ Oculomotor paralysis } & \multicolumn{2}{|c|}{ Initial measurement } & \multicolumn{3}{|c|}{ Final measurement } \\
\hline & $\begin{array}{c}\text { Range } \\
\text { (prism diopters) }\end{array}$ & $\begin{array}{c}\text { Average } \\
\text { (prism diopters) }\end{array}$ & $\begin{array}{c}\text { Range } \\
\text { (prism diopters) }\end{array}$ & $\begin{array}{r}\text { Averag } \\
\text { (prism dio) }\end{array}$ & pters) \\
\hline III & $8-55$ & 18 & $5-16$ & 8.75 & $\stackrel{0}{\geq}$ \\
\hline VI & $4-45$ & 23.9 & Orthotropia to 20 & 7 & ह \\
\hline
\end{tabular}

esotropia with an average of $18 \mathrm{PD}$. In the final measurement, the range of deviation was from 0 to $20 \mathrm{PD}$, with an average of 7 PD, in a follow-up time from 3 weeks to 2 months.

In the patients whose therapeutic plan consisted on observation, the initial measurement was from 8 to 35 PD with an average of $21 \mathrm{PD}$, and in the final measurement we could only obtain data from two patients, one in orthotropia and another with 25 PD, with a follow-up time of 1 week and 1 month, since the rest of patients did not attend further consultations.

\section{Fourth nerve paralysis}

In diabetic patients with IV nerve paralysis, the therapeutic plan in all of them consisted in observation. The initial measurement range was from 0 PD (in the primary position of gaze) to $25 \mathrm{PD}$ with an average of $6 \mathrm{PD}$, and in the final follow-up two patients were in orthotropia, in a period from 2 to 6 months. No data were obtained from the rest of patients since they did not attend subsequent consultations.

The evolution of diabetic patients with oculomotor paralysis who were injected is summarized in Table 2.

\section{Discussion}

In our series, the most affected cranial nerve overall was the $\mathrm{VI}$, with a prevalence of $41.33 \%$, similar to that found in the literature. For example, Tamhankar, et al. found involvement of the VI nerve in $56.8 \%{ }^{6}$.

The most common etiology of oculomotor paralysis was secondary to diabetes mellitus, with a prevalence of $57 \%$, a percentage higher than that published in other series, such as Akagi, et al., who reported a prevalence of $34.9 \% \%^{5}$, while Tamhankar, et al. in their prospective study, reported a higher percentage of $83.5 \%{ }^{6}$. These differences can be explained by the different types of populations studied.
The most affected cranial nerve in diabetic patients was the III in $45.29 \%$, followed by the IV with a percentage of $41.51 \%$ (both representing $86.80 \%$ of the cases). The less affected was the IV, with $13.20 \%$. The findings in our series differ from those by Al Kahtnai, et al., who concluded that the most affected nerve in the diabetic population was the VI with $53.11 \%$, followed by the III and IV with 36.36 and $2.8 \%$, respectively. However, there are differences in the population studied in this research in terms of size and period compared to the one analyzed in the population study carried out in Saudi Arabia².

All the patients with oculomotor paralysis of metabolic etiology improve without treatment; however, it has been observed in recent years that treatment with botulinum toxin shortens the duration of paralysis, with better results in patients with small strabismus ${ }^{8,9}$. In our study, improvement of the deviation was observed with the application of botulinum toxin. In the diabetic patients who were injected, four obtained orthotropia in a period of 1 week to 2 months. In addition, we observed that in patients with greater deviations, orthotropia was generally achieved in a longer period. This study has the limitation of not having a complete follow-up of some of the patients after the application of botulinum toxin.

Since the metabolic origin is the most common cause of oculomotor paralysis in our population, it is important that patients are referred to an adequate control and metabolic assessment by internists and endocrinologists, since a large percentage of patients do not know they are diabetic and hypertense until they undergo an ophthalmological assessment for having an oculomotor nerve paralysis.

\section{Conclusions}

The third cranial nerve was the most affected one in the diabetic population. Botulinum toxin provided an effective response in most cases. The therapeutic 
response of the deviation to botulinum toxin varies depending on the degree of affectation of the deviation, and the greater the degree of deviation, the slower the recovery, which allows to shorten the recovery time.

\section{Ethical disclosures}

Protection of human and animal subjects. The authors declare that no experiments were performed on humans or animals for this study.

Confidentiality of data. The authors declare that they have followed the protocols of their work center on the publication of patient data.

Right to privacy and informed consent. The authors declare that no patient data appear in this article.

\section{References}

1. Romero-Apis D. Estrabismo. Aspectos Clínicos y Tratamiento. DALA; 2010

2. Al Kahtani ES, Khandekar R, Al-Rubeaan K, Youssef AM, Ibrahim HM, Al-Sharqawi $\mathrm{AH}$. Assessment of the prevalence and risk factors of ophthalmoplegia among diabetic patients in a large national diabetes registry cohort. BMC Ophthalmology. 2016;16:118.

3. Yanovitch T, Buckley E. Diagnosis and management of third nerve palsy. Curr Opin Ophthalmol. 2007:18(5):373-8.

4. Fang C, Leavitt JA, Hodge DO, Holmes JM, Mohney BG, Chen JJ. Incidence and Etiologies of Acquired Third Nerve Palsy Using a Population-Based Method. JAMA Ophthalmol. 2017;135(1):23-8.

5. Akagi T, Miyamoto K, Kashii S, Yoshimura N. Cause and prognosis of neurologically isolated third, fourth, or sixth cranial nerve dysfunction in cases of oculomotor palsy. Jpn J Ophthalmol. 2008;52(1):32-5.

6. Tamhankar MA, Biousse V, Ying GS, Prasad S, Subramanian PS, Lee MS, et al. Isolated third, fourth, and sixth cranial nerve palsies from presumed microvascular versus other causes: a prospective study. Ophthalmology. 2013;120(11):2264-9.

7. Chan JW, Albretson J. Causes of isolated recurrent ipsilateral sixth nerve palsies in older adults: a case series and review of the literature. Clinical Ophthalmology. 2015;9:373-7.

8. Lozano TA, Hernández OT, Castillo OC, Fuente TMA. Uso de toxina botulínica subtenoniana en parálisis del sexto nervio craneal. Rev Mex Oftalmol. 2008;82(3):163-5.

9. Cáceres-Toledo $\mathrm{M}$, Márquez-Fernández $\mathrm{M}$, Cáceres-Toledo $\mathrm{O}$, Hidalgo-Costa T, Ferrás-Bacallao Y, Zazo E. Tratamiento del estrabismo paralítico con toxina botulínica A. Rev Cubana Oftalmol. 2015;28(2): 168-76.

10. Scott AB. Botulinum toxin injections into extraocular muscles as an alternative to strabismus surgery. Ophthalmology. 1980;87(10):1044-9.

11. Arroyo-Yllanes ME, Pérez-Pérez JF, Murillo-Murillo L. Resultados con la aplicación de toxina botulínica en pacientes con endotropía y retraso psicomotor. Cir Ciruj. 2009;77:9-12.

12. Dawson EL, Sainani A, Lee JP. Does botulinum toxin have a role in the treatment of secondary strabismus? Strabismus. 2005;13(2):71-3.

13. Hung HL, Kao LY, Sun MH. Botulinum toxin treatment for acute traumatic complete sixth nerve palsy. Eye. 2005;19(3):337-41. 